\title{
O PALÁCIO
}

\section{THE PALACE}

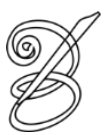

\author{
Kaveh AKBAR* \\ Purdue University \\ West Lafayette, Indiana, EUA \\ Randolph College \\ Lynchburg, Virgínia, EUA \\ Warren Wilson College \\ Swannanoa, Carolina do Norte, EUA \\ Traduzido por: \\ Layla Gabriel de OLIVEIRA** \\ Universidade Federal do Paraná \\ Curitiba, Paraná, Brasil.
}

Resumo: No poema $O$ Palácio, Kaveh Akbar explora as particularidades americanas e constrói ao seu redor uma forte crítica social e cultural. Partindo de sua vivência particular, e em verso livre, o poeta circula o que significa ser um imigrante nos Estados Unidos, abordando questões como língua, religião e pertencimento. Através de metáforas triviais, Akbar destrincha os valores americanos, sem medo de tocar em pontos sensíveis como a guerra e o conflito entre o seu país de origem e a América, esse palácio que é a grande nação dos Estados Unidos. Apesar do peso das questões abordadas, o poema é lírico e consegue manter uma sutil delicadeza nos versos, criando similes e tendo um cuidado excepcional sobre como discutir o cenário político atual sem abrir mão do poético.

Palavras-chave: Poesia. Imigração. Política. Guerra. Identidade.

Abstract: In the poem The Palace, Kaveh Akbar explores American particularities and a builds strong social and cultural criticism around it. Starting from his own experience, and in free verse, the poet circulates what it means to be an immigrant in the United States, addressing issues such as language, religion and belonging. Through trivial metaphors, Akbar unravels American values, without fear of touching sensitive points like war and the conflict between his country of origin and America, the palace that is the great nation of the United States. Despite the weight of the issues addressed, the poem is lyrical and manages to maintain a subtle delicacy in the verses, creating similes and being exceptionally careful about how to discuss the current political scenario without giving up the poetic form.

Keywords: Poetry. Immigration. Politics. War. Identity.

RECEBIDO EM: 21 de setembro de 2019

ACEITO EM: 26 de fevereiro de 2020

PUBLICADO EM: março 2020 
$\mathrm{K}$ aveh Akbar, poeta americano de imigração iraniana, nasceu no Teerã em 1989. Publicou o seu primeiro poema aos sete anos de idade, e desde então, tem foram publicados em jornais como The New Yorker, Poetry, Paris Review, Best American Poetry, The New York Times, e muitos outros. Ele é o autor de duas coletâneas completas: Pilgrim Bell (Graywolf, 2021) and Calling a Wolf a Wolf (Alice James, 2017). Ganhador do Prêmio Levis Reading, múltiplos prêmios Pushcart, e Ruth Lilly and Dorothy Sargent Rosenberg Poetry Fellowship, Kaveh é o editor-fundador do Divedapper, site de entrevistas com as maiores vozes da poesia contemporânea. Atualmente, leciona na Universidade de Purdue, EUA, e nos programas de baixa residência do MFA no Randolph College e Warren Wilson. 


\section{O PALÁCIO}

Kaveh Akbar

Traduzido por:

Layla Gabriel de Oliveira

É difícil lembrar com quem estou falando

e o porquê. O palácio queima, o palácio

é fogo

e meu trono é cômodo e

quadrado.

Lembra: o velho rei convidou seus súditos para casa

para se deliciarem com estoques de tortas de maçã e cordeiro doce. Para se deliciarem com

cordeiro doce de estórias. Ele acreditou

que eles o amavam, que a sua bondade

tinha feito ele merecer a bondade deles.

A bondade deles o arrastou para a rua

e despedaçou

seus braços, arrancou

a sua bondade, arrancou os seus dedos

feito penas.

Não há bons reis.

Só há belos palácios. 
Quem aqui poderia alegar ser meramente culpado?

Os meros.

Minha vida

ficando monstruosa

com facilidade.

Para ser um Americano meu pai deixou seus irmãos

$$
\text { pensando }
$$

que nunca os veria de novo. Meu pai

queria ser o Mick Jagger. Meu pai

virou fantasma,

374 acabou trabalhando em granjas por trinta anos, certa vez um sono

um sofá

ele cospe uma pena.

América poderia ser uma metáfora, mas não é.

Dormindo no sofá, ele cuspiu uma pena branca de pato.

Não há portas na América.

Só buracos king-size. 
Ser um Americano é ser um especialista

em oportunidade.

Oportunidade custa.

Cada laranja que eu como desaparece os milhares de pêssegos, ameixas, peras que eu poderia ter comido

mas não comi.

No céu, oportunidade custa.

No céu dela

minha mãe planta

pêssegos, ameixas, peras, e eu como até desmaiar

e acordar no céu;

acordar, e comer um pouco mais. Eu não poderia sonhar em fazer nada pela metade. Seja o que for, eu quero o ramo

todo. Por favor. E rápido.

Você ainda está ouvindo?

Cada pessoa que toco

me custa dez milhões que eu nunca vou conhecer. Pessoas e pessoas,

dentro de cada

um palácio em chamas. Dentro de cada

Mick Jagger usando um casaco de pele de gorila coberto de penas de avestruz. Ele chama de "glamouflagem". 
O que se foi, mas permanece visto?

Soldados sem sorte,

o lápis atravessa lentamente o tríceps do meu irmão.

(O que se foi, mas permanece visto?)

Ele não gritou, só deixou os olhos lacrimejarem.

Se eu sorrir, mesmo que um pouco: eles começam a afiar as espadas.

E estão certos. Agora não é hora de alegria.

376 Agora não é hora. O palácio queima.

O lápis atravessa lentamente o irmão do meu irmão.

(O que permanece, mas visto que se foi?)

Um rei governa melhor

no escuro, onde não dá pra ver suas mãos se mexendo. Um rei

não nos vê

assistindo o rei.

Costuramos as iniciais de Deus nas nossas roupas de trabalho

enquanto nossos bebês emagrecem.

Os bebês não nos veem 
assistindo nossos bebês

emagrecerem.

Nossos bebês nascidos viciados em medo de bebês.

Nossos bebês mastigando maçãs sob o sol.

América? a lápide quebrada.

América? longe o bastante de si mesma.

Alô, aqui é o Kaveh falando:

Eu queria ser o Keats

(mas já vivi quatro anos mais)

Alô, aqui é o Keats falando:

seria um absurdo dizer alguma coisa agora

(muito menos alguma coisa nova)

Alô, aqui é ninguém falando:

floradas de hibisco, penas molhadas,

(um pequeno polegar de cinzas.)

Ser Americano é ser um caçador.

Ser Americano. Quem pode ser Americano?

Ser Americano é ser? O que? Um caçador? Um caçador

que só atira grana. 
Não, grana não -

grana.

Eu tenho um aparelho de cozinha

que me permite secar alface.

Não tem jeito elegante

de dizer isso - pessoas

com corações vivos

que caberiam no meu peito

querem derreter a cidade onde eu nasci.

Na sua escola, num subúrbio americano,

a camiseta de um menino diz: "Nós Fizemos Com Hiroshima, Podemos Fazer Com Teerã!"

Na sua escola, num subúrbio americano,

a camiseta de um menino diz: "Nós Fizemos Com Hiroshima, Podemos Fazer Com Teerã!"

O troféu:

bode assado ganindo no espeto.

A camiseta de um menino diz: "Nós Fizemos Com Hiroshima, Podemos Fazer Com Teerã!" Pedem para ele virar a camiseta do avesso.

Pedem? Ele, do avesso. 
Depois que ele obedece, seus pais processam a secretária de educação.

Nossas almas querem saber

como foram feitas

o que devem.

Esses pais querem que o menino

queira derreter a minha família,

e eu vivo entre eles.

O trono do palácio. Aconchegante, em chamas.

Eu o desenho sem levantar minha caneta.

Eu o desenho gordo como a criação-

vazio como uma pegada.

Como viver? lendo poemas, respirando curto, secando alface.

América, a respiração curta

como viver?

A armadilha curta, América

capturando

só o que é pequeno demais para comer.

Os mortos se mantêm aquecidos sob a América

enquanto minha mãe frita berinjela no fogão. 
Eu não estou lá.

Eu estou em algum outro lugar da América (eu sempre estou

em algum outro lugar da América) escrevendo isso, escrevendo isso, escrevendo isso, inglês é a primeira língua da minha mãe,

mas não é a minha.

Eu poderia ter dito bademjan.

Eu poderia ter dito khodafez.

Óleo escaldante, grandes punhos de fumaça, escrevendo isso.

380 O primeiro inseto desenhado pelo homem foi o gafanhoto.

Arte é onde o que nós sobrevivemos sobrevive.

Óleo escaldante, grandes punhos de fumaça. Arte. Óleo escaldante. Arte.

Minha mãe frita berinjela. O primeiro

inseto desenhado pelo homem sobrevive.

Quem vai beijar a rainha do baile?

Cérebro pulsando como uma ostra.

Quem vai ganhar a guerra?

América emerge

coberta dos

miúdos grãos daquilo de que é feita: 
Pão fresco inchado com pó de farinha.

Ao escrever um e-mail, eu cometo um erro de digitação:

Eu te chamo tanto hoje,

e deixo assim.

Piedades proibidas, moinhos de vento girando

feito jovens bêbados.

Qualquer documento de uma civilização é também um documento de barbárie diz o palácio, em chamas.

Eu, um homem

sou tudo que eu não digo.

América, eu te garanto, se você me convidar para a sua casa

$\mathrm{Eu}$ vou ficar,

chamando, beijando meus amados com franqueza,

colhendo rabanetes

e tampando todas as suas canetas.

Não há bons reis,

só palácios em chamas.

Me chame hoje, tanto. 


\section{Original -}

\section{The Palace}

Kaveh Akbar

It's hard to remember who I'm talking to

and why. The palace burns, the palace

is fire

and my throne is comfy and

square.

Remember: the old king invited his subjects into his home

382 to feast on stores of apple tarts and sweet lamb. To feast on sweet lamb of stories. He believed

they loved him, that his goodness

had earned him their goodness.

Their goodness dragged him into the street

and tore off

his arms, plucked

his goodness out, plucked his fingers out

like feathers.

There are no good kings.

Only beautiful palaces. 
Who here could claim to be merely guilty?

The mere.

My life

growing monstrous

with ease.

To be an American my father left his siblings

believing

he'd never see them again. My father

wanted to be Mick Jagger. My father

went full ghost,

ended up working on duck farms for thirty years, once a sleep

a couch,

he coughed up a feather.

America could be a metaphor, but it isn't.

Asleep on the couch, he coughed up a white duck feather.

There are no doors in America.

Only king-sized holes.

To be an American is to be a scholar

of opportunity. 
Opportunity costs.

Every orange I eat disappears the million

peaches, plums, pears I could have eaten

but didn't.

In heaven, opportunity costs.

In her heaven

my mother grows

peaches, plums, pears, and I eat them till I pass out

and wake up in heaven;

384 wake up, and eat some more. I couldn't dream of doing anything by halves. Whatever it is, I'll take the whole bouquet. Please and soon.

Are you still listening?

Every person I touch

costs me ten million I'll never meet. Persons and persons,

inside each

a palace on fire. Inside each

Mick Jagger wearing a gorilla-pelt coat covered in ostrich feathers.

He calls it "glamouflage." 
What's gone, but still seen?

Luckless soldiers,

the pencil pushed slowly through my brother's tricep.

(What's gone, but still seen?)

He didn't scream, just let his eyes water.

If I smile even a little: they start sharpening their swords.

And they're right. This is no time for joy.

This is no time. The palace burns.

Pencil pushes slowly through my brother's brother.

(What's still, but seen gone?)

\author{
A king governs best \\ in the dark, where you can't see his hands move. A king \\ doesn't see us \\ watching the king.
}

We sew God's initials into our workshirts

while our babies get thinner.

The babies do not see us 
watching our babies

get thinner.

Our babies born addicted to fear of babies.

Our babies gumming apples in the sun.

America? the broken headstone.

America? far enough away from itself.

Hello, this is Kaveh speaking:

I wanted to be Keats

386 (but I've already lived four years too long).

Hello, this is Keats speaking:

it is absurd to say anything now

(much less anything new).

Hello, this is no one speaking:

hibiscus bloom, wet feathers,

(a tiny thumb of ash).

To be American is to be a hunter.

To be American. Who can be American?

To be American is to be? What? A hunter? A hunter

who shoots only money. 
No, not money-

money.

I have a kitchen device

that lets me spin lettuce.

There is no elegant way

to say this-people

with living hearts

that could fit in my chest

want to melt the city where I was born.

At his elementary school in an American suburb,

a boy's shirt says: "We Did It To Hiroshima, We Can Do It To Tehran!"

At his elementary school in an American suburb,

a boy's shirt says: "We Did It To Hiroshima, We Can Do It To Tehran!"

The take-home trophy:

roasted goat baying on the spit.

A boy's shirt says: "We Did It To Hiroshima, We Can Do It To Tehran!"

He is asked to turn his shirt inside out.

He is asked? His insides, out.

After he complies, his parents sue the school district. 
Our souls want to know

how they were made,

what is owed.

These parents want their boy

to want to melt my family,

and I live among them.

Palace throne. Comfy, burning.

I draw it without lifting my pen.

I draw it fat as creation-

empty as a footprint.

How to live? reading poems, breathing shallow, spinning lettuce.

America the shallow breath, how to live?

The shallow trap, America

catching

only what is too small to eat. 
The dead keep warm under America

while my mother fries eggplant on a stove.

I am not there.

I am elsewhere in America (I am always

elsewhere in America) writing this, writing this, writing this, English

is my mother's first language,

but not mine.

I might have said bademjan.

I might have said khodafez.

Sizzling oil, great fists of smoke, writing this.

The first insect drawn by man was a locust.

Art is where what we survive survives.

Sizzling oil, great fists of smoke. Art. Sizzling oil. Art.

My mother fries eggplant. The first

insect drawn by man survives.

Who to kiss the prom queen?

Brain pulsing like an oyster.

Who to win the war?

America rises 
covered in

the tiny grains of its own making:

fresh bread pocked with flour dust.

Mistyping in an e-mail I write,

I lose you so much today,

then leave it.

Forbidden mercies, windmills spinning around

like drunk teenagers.

Any document of civilization is also a document of barbarism says the palace, burning.

$$
\begin{aligned}
& \text { I, a man } \\
& \text { am what I do not say. }
\end{aligned}
$$

America I warn you if you invite me into your home

I will linger,

losing, kissing my beloveds frankly, pulling up radishes and capping all your pens.

There are no good kings, only burning palaces.

Lose me today, so much. 
‘The Palace' from Calling a Wolf a Wolf, Copyright () 2019 by Kaveh Akbar.

\section{Sobre a tradutora}

Layla Gabriel de Oliveira é poeta, atriz e estudante de Letras na Universidade Federal do Paraná. Está atualmente traduzindo o livro inédito do poeta Kaveh Akbar, Pilgrim Bell, para publicação simultânea nas duas línguas. Concluiu o seu primeiro projeto de pesquisa na Iniciação Científica sobre tradução e recepção de teatro grego, na área de Clássicas.

\footnotetext{
${ }^{*}$ Kaveh AKBAR - Graduado em Escrita Criativa e em Inglês (2012) pela Purdue University, EUA. Mestre em Escrita Criativa (poesia) pela Butler University, EUA. Doutor em Escrita Criativa (2018) pela Floria State University, EUA. Professor assistente visitante na Purdue University, West Lafayette, Indiana, EUA. Professor do programa de mestrado em Escrita Criativa na Randolph College, Lynchburg, Virgínia, EUA. Professor do mestrado para Escritores na Warren Wilson College, Swannanoa, Carolina do Norte, EUA.

Páginas profissionais: http://kavehakbar.com/\#/

https://www.cla.purdue.edu/facultyStaff/profiles/new/newfaculty-17/Akbar_Kaveh.html

http://mfa.randolphcollege.edu/faculty.html\#akbar

https://chroniclevitae.com/people/906883-kaveh-akbar/profile

** Layla Gabriel de OLIVEIRA - Graduanda em Letras - Português pela Universidade Federal do Paraná. Universidade Federal do Paraná, Setor de Ciências Humanas, Departamento de Literatura e Linguística. Curitiba, Paraná, Brasil.

Currículo acadêmico: http://lattes.cnpq.br/1282067103987880

ORCID: https://orcid.org/0000-0002-3142-6739

E-mail: laylaoliveira.ufpr@gmail.com
} 